\title{
A Wideband Printed Antenna for Covering Major Cellular Bands with a C-Shaped Patch
}

\author{
P. Misra, A. Tripathy \\ Email:pnmels@gmail.com, amaresh.silicon@gmail.com
}

\begin{abstract}
In this paper the design of a new multistandard antenna is proposed suitable for major cellular bands. A C-shaped radiator with a microstrip feed line is proposed which supports major cellular communication band like AWS, DCS, DECT, PCS, PHS, 3G, UMTS, DSR, Wi-Bro, ISM, and DMB in the range of 1.7-2.9 GHz. The designed antenna is simulated using CST Microwave Studio to achieve such wide frequency coverage. The simulation results of the designed structure in terms of return loss, VSWR and radiation pattern are presented.
\end{abstract}

Keywords: Patch, wideband, monopole, return loss

\section{Introduction}

Planar antennas are widely used in a lot of applications, because of their inherent characteristics of low cost, low profile, ease of fabrication, light, weight, conformability and integration with RF devices. Recently many antennas with multiband and wideband characteristics have been successfully designed for wireless applications [1-5]. In the design of a printed antenna, the radiator and ground plane shapes as well as the feeding structure can be optimized to achieve a broad impedance bandwidth [6-10]. With the development of wireless communications, there is a growing demand for both voice and data services. The service providers are upgrading their networks with advanced technologies since the number of mobile phone subscribers, as well as usage rate, is growing tremendously. One technique to provide such features is to integrate a multiband antenna that operates over specific narrowband frequencies such as broadband 
dual-frequency meandered monopole antenna. However, it would be extremely difficult to achieve the frequency requirements of all future communication systems accurately. Alternately, a single antenna that covers a wide range of frequencies with the same polarization would be an ideal candidate not only for present multiband applications but also for future communication systems. In this paper, a new monopole antenna with a $\mathrm{C}$ shaped radiator with a lateral feed line is proposed which supports major cellular communication band like AWS, DCS, DECT, PCS, PHS, 3G, UMTS, DSR, Wi-Bro, ISM, and DMB in the wide range of 1.7-2.9 GHz with good radiation characteristics.

\section{Antenna Design}

The geometry of proposed antenna shown in fig 1 comprises of a $50 \Omega$ microstrip line feed of width $3 \mathrm{~mm}$ on FR4 substrate (dielectric constant 4.5) of thickness 1.6 $\mathrm{mm}$ with a $\mathrm{C}$-shaped patch. The feed line is attached laterally to the radiator. The structure is analyzed by proper modeling of ground plane and patch size to operate in wideband. The antenna dimensions are given in table 1.

Ws
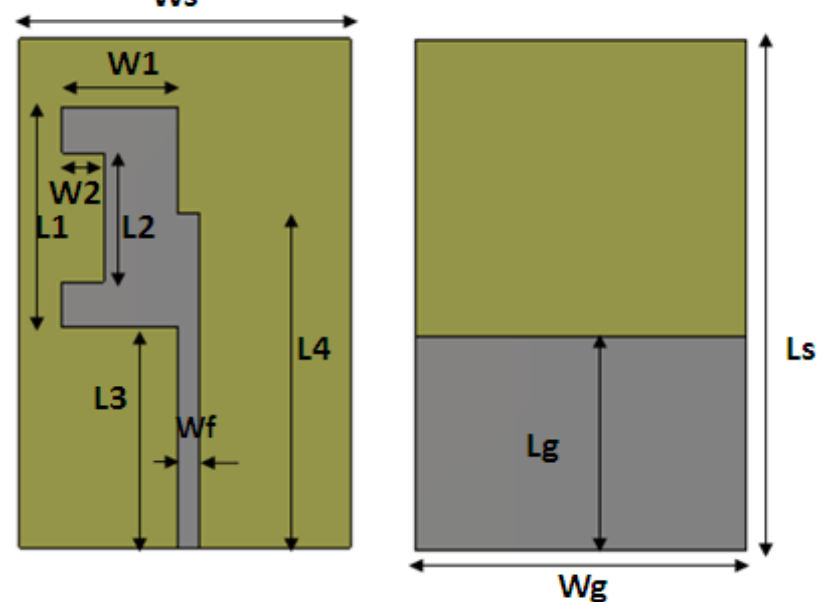

Fig 1: Proposed Antenna Geometry

Table 1: Antenna Dimensions

\begin{tabular}{cc}
\hline $\mathrm{Ws}$ & $47 \mathrm{~mm}$ \\
$\mathrm{Wg}$ & $47 \mathrm{~mm}$ \\
$\mathrm{Lg}$ & $28 \mathrm{~mm}$ \\
$\mathrm{Ls}$ & $67 \mathrm{~mm}$ \\
$\mathrm{~L} 1$ & $29 \mathrm{~mm}$ \\
$\mathrm{~L} 2$ & $17 \mathrm{~mm}$ \\
$\mathrm{~L} 3$ & $29 \mathrm{~mm}$ \\
$\mathrm{~L} 4$ & $44 \mathrm{~mm}$ \\
$\mathrm{~W}_{\mathrm{f}}$ & $3 \mathrm{~mm}$ \\
$\mathrm{~W} 1$ & $16.5 \mathrm{~mm}$ \\
$\mathrm{~W} 2$ & $6 \mathrm{~mm}$ \\
\hline
\end{tabular}




\section{Simulation Results}

The designed antenna is simulated using CST Micro- wave Studio and the return loss graph is studied to achieve wide band width and to cover the required bands.
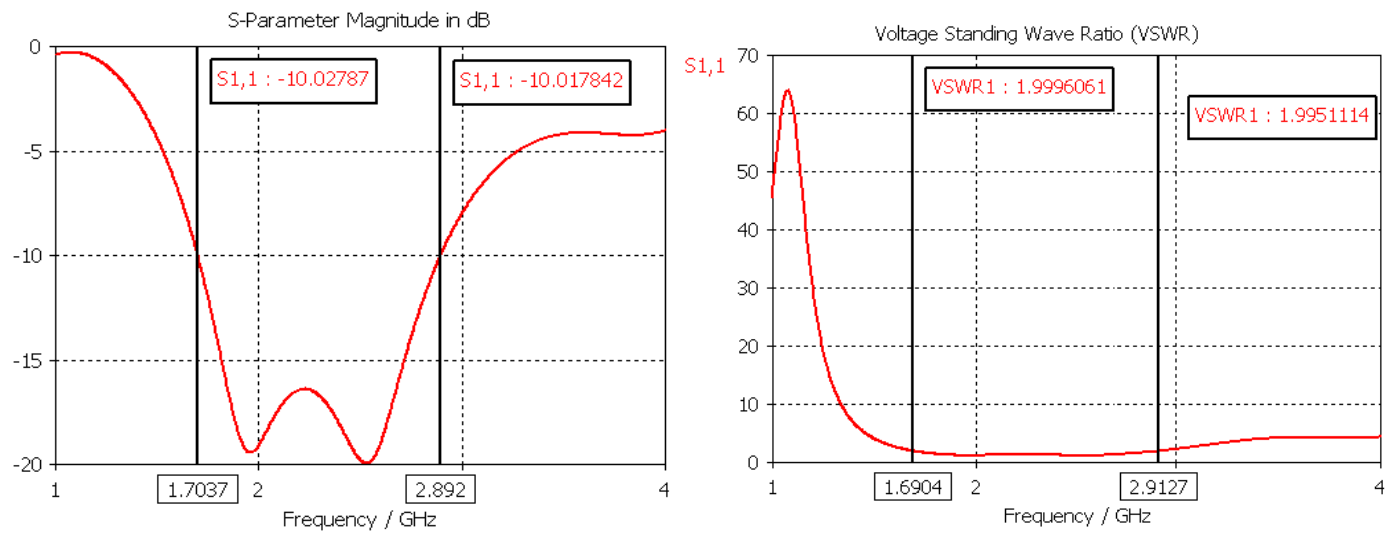

Fig 2: Simulated Return Loss and VSWR Plot

The return loss plot and VSWR plots shown in fig 2 for the designed structure satisfies the antenna operating bandwidth from 1.7 to $2.92 \mathrm{GHz}$ which fulfils the operation at desired bands.

\section{Current Distribution on Patch}

Surface current distribution shows the physical behavior of the antenna. The surface current distributions on the patch at different frequencies are studied which are given in fig 3.
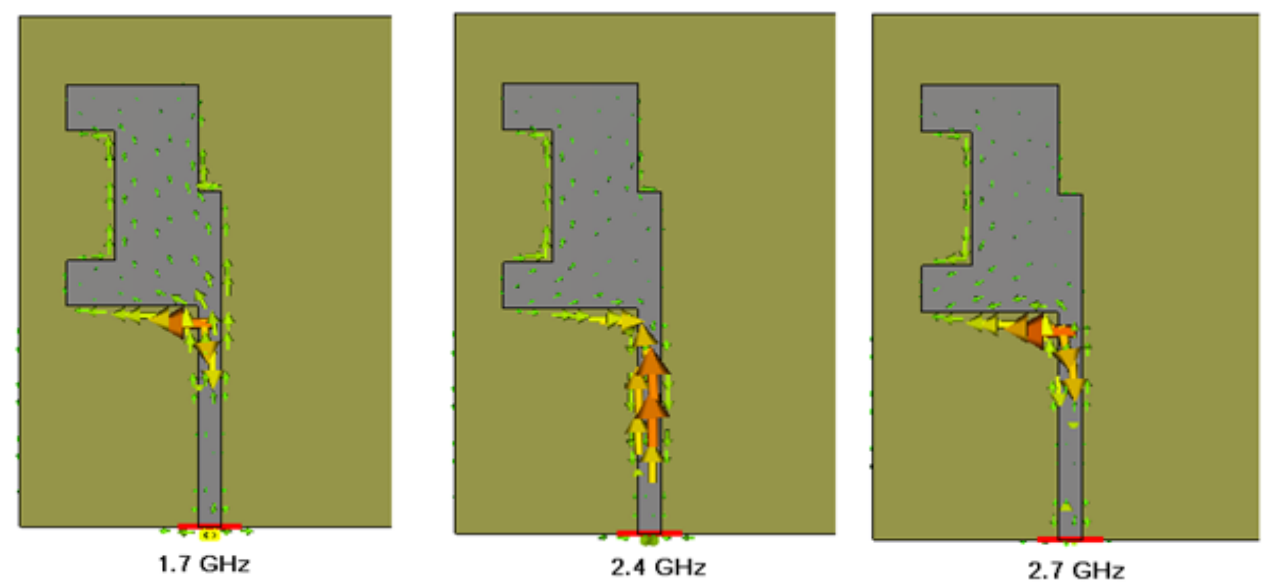

Fig 3: Surface Current Distribution 
The current distribution on the patch shows that the upper stub of C Shaped patch is responsible for lower resonant mode and lower stub is for higher resonant mode.

\section{Radiation Patterns}

The radiation patterns in terms of polar plot and 3D view are shown in figure 4 and 5 for different frequencies. The antenna gain for various bands are given in table 2. Measured antenna gains in different bands, listed in table indicate the reasonable gain offered over the entire band of operation.
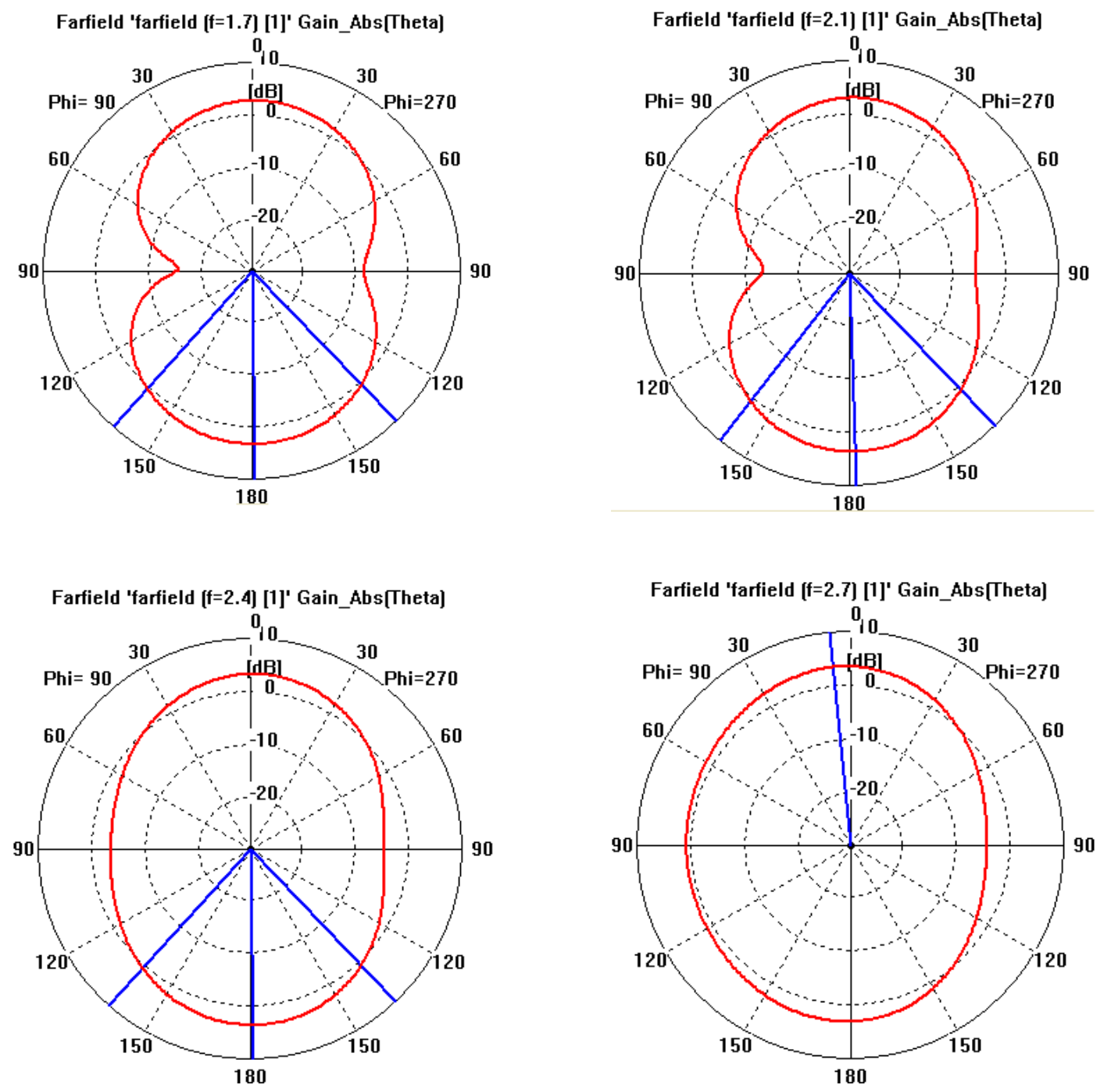

Fig 4: Radiation Patterns in terms of Polar plots 
Table 2: Antenna Gain at Different Bands

\begin{tabular}{lc}
\hline Frequency bands & Gain in dB \\
\hline AWS (1710-1755 MHz) & 3.288 \\
DCS (1710-1880 MHz) & 3.359 \\
PCS (1850-1990 MHz) & 3.509 \\
DECT (1880-1900 MHz) & 3.475 \\
PHS (1905-1920 MHz) & 3.501 \\
3G (1920-2170 MHz) & 3.615 \\
UMTS (1920-2180 MHz) & 3.618 \\
AWS (2110-2115 MHz) & 3.644 \\
DSR (2290-2300 MHz) & 3.648 \\
Wi-Bro (2300-2390 MHz) & 3.637 \\
ISM (2400-2485 MHz) & 3.599 \\
DMB (2605-2655 MHz) & 3.632 \\
\hline
\end{tabular}

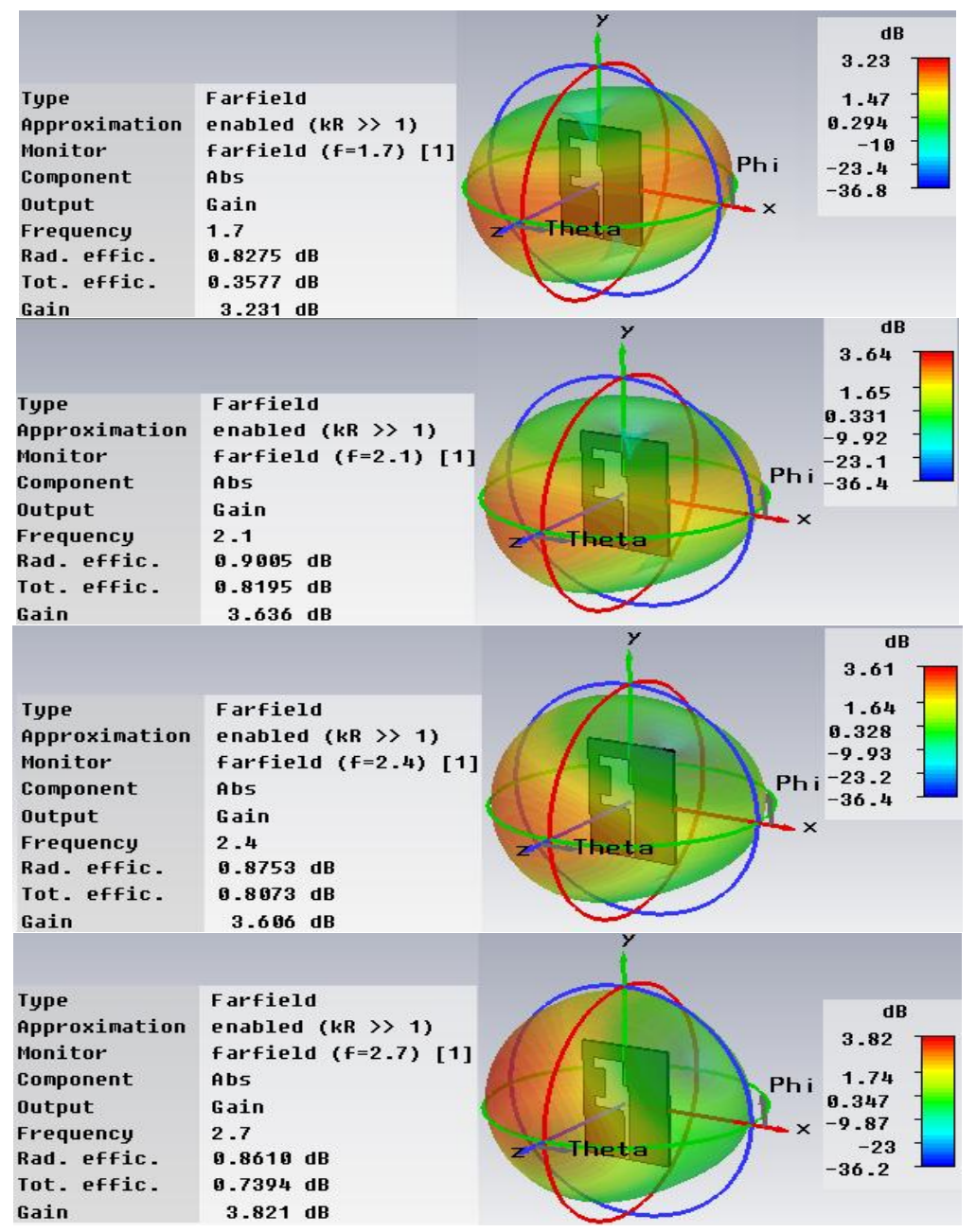

Fig 5: Radiation Patterns (3-D View) 


\section{Conclusion}

The designed antenna satisfies the wideband operation. The simulation result in terms of VSWR and return loss shows that the designed antenna is a good candidate to meet the requirement for major cellular bands with good radiation characteristics. Also the antenna is compact which makes it suitable for the cellular communication applications.

\section{References}

[1] P. Ciais, R. Staraj, G. Kossiavas, and C. Luxey, "Compact internal multiband antenna for mobile phone and WLAN standards," Electron.Lett., vol. 40, pp. 920 921, Jul. 2004.

[2] H. C. Go and Y. W. Jang, "Multi-band modified fork-shaped microstrip monopole antenna with ground plane including dual-triangle portion," Electron. Lett, vol. 40, pp. 575-577, May 2004.

[3] S. Y. Lin, "Multiband folded planar monopole antenna for mobile handset," IEEE Trans. Antennas Propag., vol. 52, no. 7, pp. 1790-1794, Jul. 2004.

[4] H. D. Chen, J. S. Chen, and Y. T. Cheng, "Modified inverted-L monopole antenna for 2.4/5 GHz dual-band operations," Electron. Lett, vol. 39, pp. 1567-1568, Oct. 2003.

[5] T. H. Kim and D. C. Park, "CPW-fed compact monopole antenna for dualband WLAN applications," Electron. Lett, vol. 41, pp. 291-293, Mar. 2005.

[6] H. S. Choi, J. K. Park, S. K. Kim and J. Y. Park, "A new ultrawideband antenna for UWB applications," Microw. Opt. Technol. Lett, vol. 40, no. 5, pp. 399-401, Mar. 5, 2004.

[7] K. Chung, H. Park and J. Choi, "Wideband microstrip-fed monopole antenna with a narrow slit," Microw. Opt. Technol. Lett., vol. 47, no. 4, pp. 400-402, Nov. 20, 2005.

[8] Y. Zhang, Z. N. Chen and M. Y. W. Chia, "Effects of finite ground plane and dielectric substrate on planar dipoles for UWB applications," in Proc. IEEE 1nl. Symp. Antennas Propagation, Jun. 2004, pp. 2512-2515.

[9] C. Waldschmidt and K. D. Pa1mer, "Loaded wedge bow-tie antenna using linear profile," Electron. Lett. vol. 37, no. 4, pp. 208-209, Feb. 2001.

[10] D. Uduwawala, M. Norgren, P. Fuks and A. W. Gunawardena, "Adeep parametric study of resistor-loaded bow-tie antennas for ground penetrating radar applications using FDTD," IEEE Trans. Geosci Remote Sensing, vol. 48, no. 4, pp. 732-742, Apr. 2004. 